\title{
A comparison of microleakage in self-etch fissure sealants and conventional fissure sealants with total-etch or self-etch adhesive systems
}

\author{
Azam Nahvi ${ }^{1}$, Alireza Razavian ${ }^{2}$, Hoorieh Abedi ${ }^{3}$, Jamshid Yazdani Charati ${ }^{4}$
}

Correspondence: Dr. Azam Nahvi

'Department of Pediatric Dentistry, Faculty of Dentistry, Mazandaran University of Medical Sciences, Sari, Iran, ${ }^{2}$ Graduate Student of Dentistry, Mazandaran University of Medical Sciences, Sari, Iran,

${ }^{3}$ Department of Operative Dentistry, Faculty of Dentistry, Mazandaran University of Medical Science, Sari, Iran,

${ }^{4}$ Department of Biostatistics, Health Sciences Research

Email: azamnahvi@yahoo.com Center, Faculty of Health, Mazandaran University of Medical Sciences, Sari, Iran

\section{ABSTRACT}

Objective: The present study was conducted to compare microleakage in self-etching fissure sealants and conventional fissure sealants with total-etch or self-etch adhesive systems. Settings and Design: This experimental in vitro study was conducted on 60 healthy third molars extracted from humans. The first group received Acid etch + Clinpro sealant, the second group received Acid etch + Single bond $2+$ Clinpro sealant, the third group received Single bond universal (self-etching bonding) + Clinpro sealant, and the fourth group received prevent seal self-etching sealant. Materials and Methods: An incision was made on the teeth after they were immersed in methylene blue 5\%. The samples were then examined under a stereomicroscope and the dye penetration rate was measured based on the Williams and Winter criteria. Statistical Analysis Used: The Kruskal-Wallis and Mann-Whitney tests were used for data analysis in SPSS-18 $(P<0.05)$. Results: Group 1 which was treated with the conventional technique (acid + fissure sealant) had the highest rate of microleakage compared to Groups 2 and $3(P<0.001)$. Conclusion: The results showed that the use of bonding results in a significant reduction in the microleakage of fissure sealants. The microleakage caused when using self-etch fissure sealant was not different from that caused by the use of the conventional method.

Key words: Bonding, fissure sealant, microleakage

\section{INTRODUCTION}

Dental caries is the most common bacterial disease affecting humans. Occlusal pits and fissures are the most susceptible area for the development of caries. Fissure sealants provide a mechanical barrier against microorganisms and plaques by filling the pits

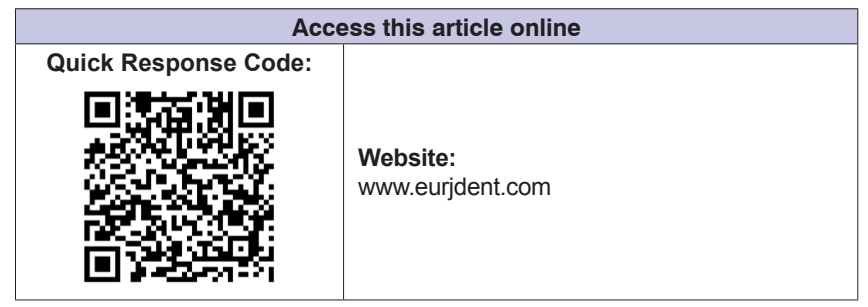

and fissures and comprise an effective way for the prevention of caries..$^{[1-3]}$ Young permanent molars are at an increased risk of decay due to the complicated morphology of the occlusal surface ${ }^{[4]}$ In 1895 , Wilson

This is an open access journal, and articles are distributed under the terms of the Creative Commons Attribution-NonCommercial-ShareAlike 4.0 License, which allows others to remix, tweak, and build upon the work non-commercially, as long as appropriate credit is given and the new creations are licensed under the identical terms.

For reprints contact: reprints@medknow.com

How to cite this article: Nahvi A, Razavian A, Abedi H, Charati JY A comparison of microleakage in self-etch fissure sealants and conventional fissure sealants with total-etch or self-etch adhesive systems. Eur J Dent 2018;12:242-6.

DOI: 10.4103/ejd.ejd_63_18 
Nahvi, et al.: A comparison of microleakage in self-etch fissure sealants and conventional fissure sealants

used a dental cement as a fissure sealant for the first time. ${ }^{[5]}$ The failure of fissure sealants is mainly due to the inadequate isolation and the contamination of the etched enamel with saliva. ${ }^{[6,7]}$ The conventional way to use fissure sealants is to use acid etch, wash, dry and then place, and cure the sealant. ${ }^{[8]}$ Inappropriate isolation and the surface contamination of the enamel during the application of sealant affect its degree of effectiveness and retention. The fast clinical application of the sealant is, therefore, very important. ${ }^{[9]}$

Self-etch sealants have been introduced in recent years with the acid etching and washing steps eliminated and providing a good alternative to the standard acid-etch system, especially for children with behavioral problems and severe nausea refluxes or those unable to cooperate. ${ }^{[10,11]}$ The available studies are focused on techniques that improve the retention of fissure sealants using adhesives as an intermediate layer between the etched enamel and the sealant resin. ${ }^{[12]}$ Other studies have investigated self-etching adhesives for simplifying the sealant process and have achieved different results in comparison with the standard total-etch technique. ${ }^{[13,14]}$

A newer version of the self-etch fissure sealant has been introduced that facilitates this process, and the designers claim that the new sealant yields acceptable results. ${ }^{[15]}$ Among these newly released self-etching fissure sealants is prevent seal (Itena Clinical, USA). The designers of prevent seal claim that this technology needs no etching, washing, and drying and works in one simple step. ${ }^{[16]}$ Microleakage is the passage of bacteria, fluids, molecules, and ions between the cavity wall and the restorative material. ${ }^{[1,17]}$ The sealant capacity to prevent microleakage in fissures is an important factor to evaluating the clinical success of such materials since microleakage can also affect the process of decay under the sealant. ${ }^{[18-20]}$

The dye penetration method is inexpensive and nontoxic and is most widely used, and it also enables detection in low concentrations. ${ }^{[21]}$

The study of the microleakage of self-etching fissure sealants using the standard total-etch technique is required for assessing the use of self-etch sealants. Since few in vitro and in vivo studies have been conducted on self-etching fissure sealants till date, this study was conducted to compare the rate of microleakage in self-etching fissure sealants and in conventional fissure sealants using the total-etch or self-etch adhesive systems.

\section{MATERIALS AND METHODS}

This experimental in vitro study examined 60 permanent third molars extracted over 3 months. All the selected teeth were washed with normal saline and kept in the solution until the experiment. The selected teeth were free of any caries, cracks, fractures, and restorations, and were randomly divided into four groups of 15 as follows:

- The first group: The teeth were prepared after washing and drying for prophylaxis with pumice powder. Their occlusal fissures were then etched for $20 \mathrm{~s}$ using a phosphoric acid gel 35\% (Ultra-Etch, Ultra dent Products Inc., South Jordan, UT, USA). After etching, the teeth were washed for $15 \mathrm{~s}$ and dried. In the next step, Clinpro Sealant (3M ESPE, Minnesota, USA) was placed into the occlusal fissures, and its excess was removed by a hair applicator and the bubbles were removed by a catheter and the sealant was then cured for $20 \mathrm{~s}$

- The second group: In this group, all the steps before placing the fissure sealant were similar to the first group. According to the manufacturer's instructions, the surface of the tooth was etched by an etching agent for $20 \mathrm{~s}$, and the dentin bonding agent called single bond (3MESPE, Minnesota, USA) was then used according to the manufacturer's instructions and exposed to light with a light cure device for 10 s. Finally, Clinpro fissure sealant was injected into the fissures

- The third group: This group used the seventh-generation all-in-one self-etching bonding system (single bond universal self-etch, 3MESPE, Minnesota, USA) according to the manufacturer's instructions. The adhesive was applied to the surface of the teeth for $20 \mathrm{~s}$, then air-dried gently for $5 \mathrm{~s}$, and cured for $10 \mathrm{~s}$. Clinpro fissure sealant was then placed on it

- The fourth group: The prepared samples were dried for $15 \mathrm{~s}$ and prevent seal (Itena, USA) was placed into the fissures. The bubbles were then checked with a catheter and the sealant was cured for $20 \mathrm{~s}$.

All the samples were cured with a standard light cure device (3M, St. Paul, Minnesota) under identical conditions regarding device power and distance from the tooth. After the sealants were placed on the occlusal surface and hardened, the entire sealant surface, in particular, the sealant and tooth contact area were examined for defects and potential bubbles using a 23-G catheter to ensure that the samples 
were in a completely good condition. After applying the fissure sealants, the samples were exposed to 500 heat cycles between $5^{\circ} \mathrm{C}$ and $55^{\circ} \mathrm{C}$ in a thermo cycler. Each cycle consisted of $20 \mathrm{~s}$ of placement in a hot water reservoir $\left(55^{\circ} \mathrm{C}\right), 20 \mathrm{~s}$ of placement in a cold water reservoir $\left(5^{\circ} \mathrm{C}\right)$, and $10 \mathrm{~s}$ of transfer from one reservoir to another. After the thermal cycle, all the samples were prepared for placement in a dye solution. The apex of all the teeth was sealed with wax and covered with two layers of nail lacquer up to a 1-mm margin of the sealant. The teeth were then incubated in methylene blue $5 \%$ for $24 \mathrm{~h}$, to allow the possible penetration of the dye matter in the distance between the enamel and the fissure sealant material. The teeth were placed in an acrylic mold up to the CEJ area. A parallel incision was then made on the longitudinal axis of the tooth in the buccolingual direction and in the central mesiodistal width using a water-cooled diamond blade on a Labcut 250B cutting machine (Extec Corp, Enfield, CT, USA). The section was examined under a stereomicroscope ( $\times 40$ magnification). The dye penetration yielded was categorized based on the Williams and Winter criteria as shown in Table 1. ${ }^{[22]}$

An observer blinded to the treatments graded the dye penetration. Descriptive statistics (frequency tables) and the Kruskal-Wallis test were used to compare the four groups regarding the rate of microleakage due to their graded nature. Mann-Whitney test was used for the post hoc comparisons. Data were analyzed in SPSS 18 program (SPSS Inc. Chicago, IL, USA) at a statistical significance level of $P \leq 0.05$.

\section{RESULTS}

The Kruskal-Wallis test was used to compare the microleakage grades between the four groups [Table 2 and Figure 1]. The microleakage grades obtained in the four groups can be summarized as below: Group $1>$ Group $4>$ Group 3 > Group 2.

According to Table 1, in Group 1, the highest frequency of microleakage was Grade 3 and the lowest Grade 0 and 1. In Group 2 and 3, the highest frequency of microleakage was Grade 1 and the lowest Grade 3. In Group 4, the highest frequency of microleakage was Grade 2 and 3 and the lowest Grade 0.

Mann-Whitney test was used for the pairwise comparisonofthegroups[Table3]. Therewasasignificant difference between Groups 1 versus 2 and $3(P<0.001)$. Group 1 had more microleakage. While there were no

\begin{tabular}{ll} 
Table 1: Williams and Winter score for dye penetration \\
\hline Grades & Dye penetration \\
\hline Grade 0 & $\begin{array}{l}\text { No dye penetration between the tooth } \\
\text { surface and the sealant } \\
\text { Dye penetration into less than one-third of the entire length } \\
\text { of the surface between the sealant and the tooth structure }\end{array}$ \\
Grade 2 & $\begin{array}{l}\text { Dye penetration into one-third to two-thirds } \\
\text { of the entire length of the surface between } \\
\text { the sealant and the tooth structure } \\
\text { Dye penetration into more than two-thirds of the entire } \\
\text { length of the surface between the sealant and the tooth } \\
\text { structure }\end{array}$
\end{tabular}

\begin{tabular}{lccccc} 
Table 2: Dye penetration score for all the groups \\
\hline Group & \multicolumn{5}{c}{ Dye penetration scores } \\
\cline { 2 - 6 } & $\mathbf{0}$ & $\mathbf{1}$ & $\mathbf{2}$ & $\mathbf{3}$ & $\boldsymbol{n}$ \\
\hline 1 & 0 & 0 & $5(32)$ & $11(68)$ & $16(100)$ \\
2 & $6(37)$ & $7(44)$ & $3(19)$ & 0 & $16(100)$ \\
3 & $2(12)$ & $8(50)$ & $5(32)$ & $1(6)$ & $16(100)$ \\
4 & 0 & $2(12)$ & $7(44)$ & $7(44)$ & $16(100)$ \\
\hline
\end{tabular}

Kruskal-Wallis test. Group 1: Acid etch + Clinpro sealant, Group 2: Acid etch + single bond $2+$ Clinpro sealant, Group 3: Single bond universal (self-etching bonding) + Clinpro sealant, Group 4: Prevent seal self-etching sealant

\begin{tabular}{|c|c|}
\hline Groups & $P$ \\
\hline 1 and 2 & $<0.001$ \\
\hline 1 and 3 & $<0.001$ \\
\hline 1 and 4 & $<0.17$ \\
\hline 2 and 3 & $<0.11$ \\
\hline 2 and 4 & $<0.001$ \\
\hline 3 and 4 & 0/002 \\
\hline
\end{tabular}

significant differences between Groups 1 and 4, as well as 2 and 3. There was a significant difference between Groups 2 and $4(P<0.001)$, and also 3 and $4(P=0.002)$. Group 4 had more microleakage.

\section{DISCUSSION}

Microleakage is a decisive factor in the performance of a fissure sealant. ${ }^{[15]}$ In this study, microleakage was detected in all four groups. ${ }^{[18]}$

The sealant used in this study was Clinpro, which is an unfilled sealant. Unfilled sealants have a lower viscosity, which results in a greater penetration in small spaces and a stronger bonding in the deep layers of the enamel. ${ }^{[23]}$ This study did not perform enameloplasty because according to the results of other studies, ${ }^{[24]}$ differences in depth of fissures do not make a significant difference in the resultant 
Nahvi, et al.: A comparison of microleakage in self-etch fissure sealants and conventional fissure sealants

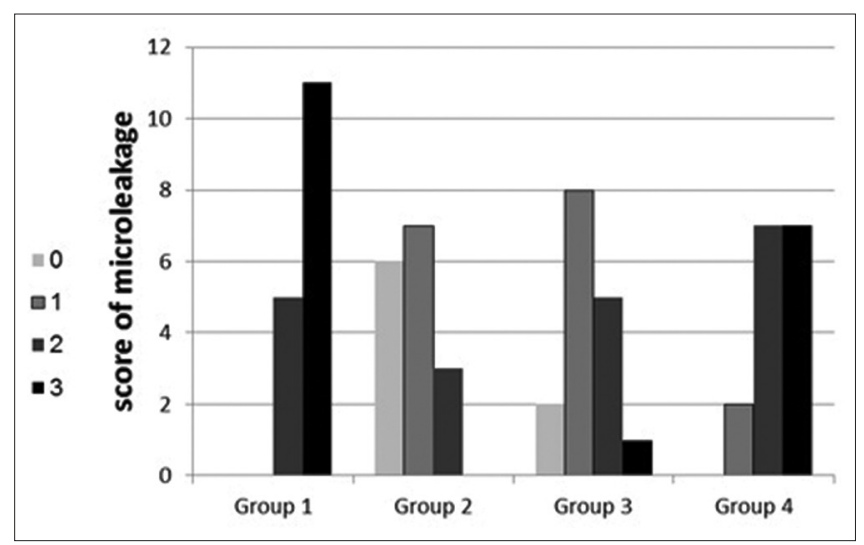

Figure 1: Comparative illustration of the groups as follows: Grade 0: no dye penetration between the tooth surface and the sealant, Grade 1: dye penetration into less than one-third of the entire length of the surface between the sealant and the tooth structure, Grade 2: dye penetration into one-third to two-thirds of the entire length of the surface between the sealant and the tooth structure, and Grade 3: dye penetration into more than two-thirds of the entire length of the surface between the sealant and the tooth structure

microleakage and also because the objective was to separately study the effect of the materials and their technique of use.

In this study, the rate of microleakage was higher in Group 1 (conventional method of acid etching + fissure sealant) compared to all the other groups. In an in vitro study, Biria et al. ${ }^{[17]}$ compared the microleakage rate of a self-etching fissure sealant (Enamel Loc) with a conventional fissure sealant in molar teeth and concluded that the microleakage rate of self-etching fissure sealant is significantly higher than that of conventional fissure sealant (with acid etching) and conventional fissure sealant with bonding. The difference between the results of the cited study and the present research maybe due to the different laboratory conditions, sample sizes, and types of tooth examined and most importantly, types of self-etching fissure sealants used. According to the manufacturers, one of the predominant features of prevent seal is its low viscosity, which makes it suitable for penetrating the tooth fissures. ${ }^{[1]}$

In this study, the microleakage grade was higher in Group 1 than in Group 3 and also in Group 3 than in Group 2; however, no significant differences were observed between Groups 2 and 3. This finding suggests that the use of bonding before the conventional method reduces microleakage significantly. Furthermore, the use of self-etching bonding is less effective in reducing microleakage compared to when the acid-etching + bonding method is used. This study showed that regardless of the bonding system used, the rate of microleakage decreases by adding bonding, which is consistent with the results obtained by Borem and Feigal ${ }^{[25]}$ and Pérez-Lajarín et al. ${ }^{[20]}$ The use of bonding before the sealant is still under debate. This additional step is time-consuming and is not cost-effective. ${ }^{[9]}$ In a clinical study conducted by Mascarenhas et al. ${ }^{[26]}$ with a 5-year follow-up, the use of bonding before sealing was found to not make a difference in sealant retention. Boksman et al..$^{[27]}$ examined the clinical effect of bonding before fissure sealing. After 2 years, they concluded that bonding does not increase the amount of retention in the long run. The present findings are in line with the results of many studies to the effect that the use of bonding reduces microleakage. $[7,18,20,25,28]$

The use of bonding agents before placing the sealant decreases microleakage and the risk of caries; however, it also increases the application time and the risk of saliva contamination, especially in uncooperative children and in newly erupted teeth. The recent advantage noted for bonding has the potential to make this technique more acceptable for older patients. The self-etch bonding approach is very promising regarding ease of application and technical sensitivity. Due to the acidic monomers contained in the product and these products do not require separate acid etching and washing steps. ${ }^{[18]}$

In general, the disparities between the results of some studies can be due to the type of study, the impossibility of reproducing the exact same conditions in two different environments, the type of fissure sealant, and bonding used and the conditions under which the study has been performed such as the duration of etching or the thermocycling conditions. ${ }^{[29]}$

Being an in vitro study, the present research did not evaluate the effect of clinical problems such as saliva control and patient cooperation on the results. Clinical studies with longer follow-up periods are, therefore, needed for determining the effectiveness of these materials more precisely.

Desirable features such as 21-MPa retention with the enamel, fluoride release, low viscosity, and ease of application have made prevent seal more suitable for sealing posterior occlusal fissures compared to the sole use of the total-etch technique. Nonetheless, since a lower leakage was observed in the groups for which bonding was performed and fissure sealing with bonding is taken to be the gold standard in this study. 


\section{CONCLUSION}

The results showed that the use of bonding results in a significant reduction in the microleakage of fissure sealants compared to when no bonding is used. Fifth generation bonding is also more effective than seventh generation bonding. The microleakage caused when using self-etch fissure sealant was not different from that caused with the use of the conventional method.

\section{Financial support and sponsorship}

Nil.

\section{Conflicts of interest}

There are no conflicts of interest.

\section{REFERENCES}

1. Jabbarifar SE, Ghasemi D, Barekatain M, Alizadeh F, Tahmourespoor S. In vitro comparison of microleakage of a self-etching fissure sealant with a flowable composite resin and a conventional fissure sealant. J Isfahan Dent Sch 2014;10:259-65.

2. Ripa LW. Sealants revisted: An update of the effectiveness of pit-and-fissure sealants. Caries Res 1993;27 Suppl 1:77-82.

3. Simonsen RJ. Retention and effectiveness of dental sealant after 15 years. J Am Dent Assoc 1991;122:34-42.

4. Nogourani MK, Janghorbani M, Khadem P, Jadidi Z, Jalali S. A 12-month clinical evaluation of pit-and-fissure sealants placed with and without etch-and-rinse and self-etch adhesive systems in newly-erupted teeth. J Appl Oral Sci 2012;20:352-6.

5. Kiremitçi A, Yalçin F, Gökalp S. Bonding to enamel and dentin using self-etching adhesive systems. Quintessence Int 2004;35:367-70.

6. Grande RH, Ballester R, Singer Jda M, Santos JF. Microleakage of a universal adhesive used as a fissure sealant. Am J Dent 1998;11:109-13.

7. Hebling J, Feigal RJ. Use of one-bottle adhesive as an intermediate bonding layer to reduce sealant microleakage on saliva-contaminated enamel. Am J Dent 2000;13:187-91.

8. Honarmand M, Amiri N, Khazaei A, Hossini BA, Khalafinejad F. Extra-oral comparison of conventional acid-etch technique with self-etch systems in relation to microleakage of fissure sealants in permanent teeth. J Isfahan Dent Sch 2013;2:135-43.

9. Yazıcı R, Yıldırım Z, Tuncer D, Berber A, Başeren M. Effects of self-etch adhesives on microleakage of fissure sealants. Clin Dent Res 2013;37:9-24

10. Burbridge L, Nugent Z, Deery C. A randomized controlled trial of the effectiveness of a one-step conditioning agent in sealant placement: 6-month results. Int J Paediatr Dent 2006;16:424-30.

11. Ram D, Mamber E, Fuks AB. Clinical performance of a non-rinse conditioning sealant in three paediatric dental practices: A retrospective study. Int J Paediatr Dent 2005;15:61-6.

12. Van Meerbeek B, De Munck J, Yoshida Y, Inoue S, Vargas M, Vijay P, et al. Buonocore memorial lecture. Adhesion to enamel and dentin: Current status and future challenges. Oper Dent 2003;28:215-35.

13. Feigal RJ, Quelhas I. Clinical trial of a self-etching adhesive for sealant application: Success at 24 months with prompt L-pop. Am J Dent 2003;16:249-51.

14. Venker DJ, Kuthy RA, Qian F, Kanellis MJ. Twelve-month sealant retention in a school-based program using a self-etching primer/adhesive. J Public Health Dent 2004;64:191-7.

15. Biria M, Ghasemi A, Torabzadeh H, Shisheeian A, Baghban AA. Assessment of microshear bond strength: Self-etching sealant versus conventional sealant. J Dent (Tehran) 2014;11:137-42.

16. Javadinejad S, Borojeni PM, Saleki M, Hajizadeh F. Clinical comparison of a self-etching fissure sealant with a conventional sealant: A 12-month follow-up. J Isfahan Dent Sch 2012;8:99-108.

17. Biria M, Ghasemi A, Doroudgar K, Najafi AS. An Experimental Micro Leakage Study of Two Self-Etch and One Total-Etch Fissure Sealants. The Journal of Islamic Dental Association of IRAN (JIDA). 2011;23:182-8.

18. Asselin ME, Fortin D, Sitbon Y, Rompré PH. Marginal microleakage of a sealant applied to permanent enamel: Evaluation of 3 application protocols. Pediatr Dent 2008;30:29-33.

19. Ben-Amar A, Liberman R, Judes H, Nordenberg D. Long-term use of dentine adhesive as an interfacial sealer under class II amalgam restorations. J Oral Rehabil 1990;17:37-42.

20. Pérez-Lajarín L, Cortés-Lillo O, García-Ballesta C, Cózar-Hidalgo A. Marginal microleakage of two fissure sealants: A comparative study. J Dent Child (Chic) 2003;70:24-8.

21. Alani AH, Toh CG. Detection of microleakage around dental restorations: A review. Oper Dent 1997;22:173-85.

22. Williams B, Price R, Winter GB. Fissure sealants. A 2-year clinical trial. Br Dent J 1978;145:359-64.

23. Birkenfeld LH, Schulman A. Enhanced retention of glass-ionomer sealant by enamel etching: A microleakage and scanning electron microscopic study. Quintessence Int 1999;30:712-8.

24. Hannig M, Gräfe A, Atalay S, Bott B. Microleakage and SEM evaluation of fissure sealants placed by use of self-etching priming agents. J Dent 2004;32:75-81.

25. Borem LM, Feigal RJ. Reducing microleakage of sealants under salivary contamination: Digital-image analysis evaluation. Quintessence In 1994;25:283-9.

26. Mascarenhas AK, Nazar H, Al-Mutawaa S, Soparkar P. Effectiveness of primer and bond in sealant retention and caries prevention. Pediatr Dent 2008;30:25-8.

27. Boksman L, McConnell RJ, Carson B, McCutcheon-Jones EF. A 2-year clinical evaluation of two pit and fissure sealants placed with and without the use of a bonding agent. Quintessence Int 1993;24:131-3.

28. Tulunoğlu $\mathrm{O}$, Bodur $\mathrm{H}$, Uçtaşli $\mathrm{M}$, Alaçam A. The effect of bonding agents on the microleakage and bond strength of sealant in primary teeth. J Oral Rehabil 1999;26:436-41.

29. Bahrololoomi Z, Soleymani A, Heydari Z. In vitro comparison of microleakage of two materials used as pit and fissure sealants. J Dent Res Dent Clin Dent Prospects 2011;5:83-6. 